\title{
Game Addiction is Included in Mental Illness and Medical Care is A Challenge: Textual and Discourse Analysis
}

\section{Yi-Sheng Wang* Chao-Feng Lin}

Oriental Institute of Technology, New Taipei City, Taiwan, ROC

*Corresponding Author: Yi-Sheng Wang, Oriental Institute of Technology, New Taipei City, Taiwan, ROC, Email: winsome5@ms39.hinet.net

\begin{abstract}
The popularity of smartphones and mobile communications has made mobile phones and game addictions like "electronic opium" spread. The World Health Organization (WHO) officially listed "gaming disorders" as mental illness at the beginning of this year. In 2018, it is expected to encourage more experts to invest in relevant medical research, so that addicts have more resources to seek help. The researchers used the method of Textual and Discourse Analysis. The narrative document not only reflects norms, but also shapes norms: human behavior is based on social structure, but in turn constructs social structures. The findings are that human beings are destined to live in a virtual world. There is no good or evil, only how to choose. We can also use the electronic virtual world to help our lives.
\end{abstract}

Keywords: Game Addiction; Mental Illness; Medical Care; Discourse Analysis

\section{Introduction}

At the beginning of this year, the World Health Organization (WHO) (2018) [1] included "gaming disorder" in the new edition of the International Classification of Diseases and Related Health Problems (ICD), which listed our commonly known "game addiction" as gambling. One of the addictive behaviors of abnormal problems such as hoarding disease, as a new medical reference standard, the relevant regulations came into effect in 2018 [2,3].

According to the WHO (2018) [1] about 2\% to 3\% of the global game population has game barriers, and three criteria for "game disorder" are listed: (1) Loss of control over the game play (the frequency, intensity, and time of playing the game should be taken into account); (2) The importance of the game is higher than other interests in life; (3) If you know that the game will have a negative impact, you still choose to continue playing the game. In fact, if you look at the above three points, perhaps many people have similar symptoms, but WHO has more stringent regulations on addiction. Generally speaking, the above-mentioned addiction indicators must appear for 12 
consecutive months, seriously affecting family and social. It is possible to be diagnosed as an addiction by studying, working, and working [4].

\section{Literature Review}

\subsection{Medical Care is a Challenge}

The latest version of the International Classification of Diseases and Related Health Problems (2018) [5] officially lists game addiction as a form of mental illness, and WHO will continue to inform governments to incorporate game addiction into the health care system [6]. At the beginning of the year, when WHO (2018) first listed "game disorder" in the list of mental illnesses, it caused a discussion. The fifth edition of the psychology diagnostic manual DSM-V, which is currently used by psychologists, has not listed game addiction as Disease is only considered to be a case that requires further research. There is also a group of people who are worried that this may deepen the unnecessary panic when parents judge whether their children are "game lovers" or "addicts". Some people may not be addicted, but they may be classified as a kind of Diseases, how countries will take care of medical care will be a big challenge. And in the era of rapid technological evolution, playing electric power may also have social interaction components. Today, digital life and daily life have been blended to some extent, so parents do not have to panic because of the latest revision of WHO. Forcing isolation from video games is not necessarily the best practice [7].

In addition, the doctor will not immediately start to diagnose the "game disorder" of the patient, because the latest revised version of ICD-11 must be voted at the World Health Assembly in May 2019. It will not be implemented until January 2022, and WHO will only promote it to all countries in the world. It does not have the right to require countries to adopt it. Governments still have the right to adopt it (WHO, 2018) [1].

\subsection{Asian Countries Face Game Addiction Practices}

According to statistics, there are currently about 2.6 billion game populations in the world [8]. With the well-known game Fortnite, the average annual revenue will be 300 million US dollars [20]. The global annual revenue of the game industry is estimated to grow 31\% within 3 years. Reached $\$ 180$ billion [9]. The video game industry is not just entertainment. There are huge economic benefits and industrial ecosystems behind it. Universities in many Asian countries have even officially added e-sports departments [10].

Of course, while taking into account the development of the industry, the government must also take into account the healthy development of the whole people and propose good supporting measures [11]. For example, if Singapore has a casino to develop sightseeing, the local government will set strict regulations and must be 21 years old to enter the casino. You must also pay an additional entrance fee. If you find that your relatives are addicted, you can apply for a "ban". The electric industry is the same. The countries in the world must face the development of the video game industry and must also address the addiction [11]. 


\subsection{Research Methods}

The researchers used the method of Textual and Discourse Analysis [12,13]. On the one hand, for discussion; on the other hand, for text analysis. The characteristics of narrative analysis are not limited to the text itself, but also analyze the text construction situation: avoiding the simple review of the "text itself", but should include the social history of constructive discussion into the analysis, so that the analytical argument is more grounded and can provide more multiple insights [14]. Therefore text analysis is part of the narrative analysis [15-17].

The narrative document not only reflects norms, but also shapes norms: human behavior is based on social structure, but in turn constructs social structures [12,18].

\subsection{Finding}

\subsubsection{South Korea}

The South Korean authorities passed a bill in 2011 that requires ID certification for online games. Teenagers under the age of 16 cannot play online games between midnight and 6 am to help young people overcome Internet addiction [1].

\subsubsection{China}

In July 2017, Tencent China launched an anti-addiction mechanism on the "Glory of the Kings" game platform to regulate the playing time of underage users [10].

Users under the age of 12 will be online for up to 1 hour per day, and logins will be prohibited after 9:00 PM; minors over 12 years of age will be online for up to 2 hours per day, and will be forced to go offline after the timeout. At the same time, in order to prevent underage users from logging in with other accounts, the player's account will be bound to the hardware device, and the parent can force the offline setting of the bound device [19].

\subsubsection{Taiwan}

Taiwan's Weifu Department also followed the latest WHO draft to include game addiction as one of the mental illnesses. However, at this stage, there is no health insurance diagnostic code for game addiction. At present, doctors use anxiety syndrome when they are diagnosed with addiction. Depression, impulsive control disorder as a diagnosis result, because Taiwan adopts WHO's diagnostic classification system, with the latest revision of the WHO, the new game addiction health care diagnostic code will not be excluded in the future [1].

In addition, in the past, the Director of the Department of Psychology and Oral Health of the Department of Health and Welfare, Li Lizhong, said that in the future, Taiwan hopes that Taiwan can use the Korean standard to restrict the use of the Internet by the underage users in the middle of the night. However, the relevant regulations also need to integrate the video game operators to import the real-name system. Only when the consensus of the whole people is reached will it be possible to formulate relevant management norms [1]. 
Fortune J Health Sci 2018; 1 (2): 026-030

2.5 Why is video games always addictive?

According to one statistic, there are 155 million gamers in the United States alone, 44\% of whom are women. Regardless of the location and source of the statistics, the video game industry has been unable to withstand the savage beasts and produce by-products such as game reviews (such as Pewdiepie and the Unified God) and athletic competitions [4]. Video games are an uncompromising force, and this is an indisputable fact. From my childhood Nintendo, Gameboy to today's diverse video game companies, video games have proved to be an intractable attraction, like an open flame, but human beings are flying insects [6].

Why are video games always addictive? A number of theories, some say that some people are Loser in the real world, they are anesthetizing themselves in video games, we can always find young people who lose their will in the Internet cafes; others say that video games meet the needs of human beings in reality [7]. Unexpected illusions, such as human sinful desires, are met in the GTA; others say that the entire design of electronic play, by the picture, the statement, the gameplay, is aimed at increasing the adrenaline, so it is impossible to stop [8].

However, those theories are just scorpions, and they can only tell one side of video games [2]. If Loser loves video games, the socially-labeled Loser is really easy to indulge in video games and can't live normally, but there are also many so-called successful people who also play video games [8]. They also play well, and children are easy to indulge. A group of video games, how can they be frustrated as adults in real life?

The main reason for indulging in video games is not the theory mentioned above, but the fact that video games have an instant positive feedback system, which is a common feature of all games and even all virtual worlds (such as social media) [2]. Human beings are very sensitive to positive feedback. If the positive response of a certain behavior is faster, then more motivation and pleasure will be obtained. In psychology, it is also called conditioning [2].

\section{References}

1. World Health Organization (WHO) (2018). Gaming disorder. http://www.who.int/

2. Hussain Z, Williams GA and Griffiths. An exploratory study of the association between online gaming addiction and enjoyment motivations for playing massively multiplayer online role-playing games. Computers in Human Behavior 50 (2015): 221-230.

3. Li H, Liu Y, Xu X, Heikkilä J and Heijden HVD. Modeling hedonic is continuance through the uses and gratifications theory: An empirical study in online games. Computers in Human Behavior 48 (2015): 261-272.

4. Badrinarayanan VA, Sierra JJ and Martin KM. A dual identification framework of online multiplayer video games: The case of massively multiplayer online role playing games (MMORPGs). Journal of Business Research 68 (2015): 1045-1052.

5. International Classification of Diseases and Related Health Problems (2018). ICD purpose and uses. 
http://www.who.int/classifications/icd/en/

6. Chang IC, Liu CC and Chen K. The effects of hedonic/utilitarian expectations and social influence on continuance intention to play online games. Internet Research 24 (2014): 21-45.

7. Davis R, Lang B and Gautam N. Modeling utilitarian-hedonic dual mediation (UHDM) in the purchase and use of games, Internet Research 23 (2013): 229-256.

8. Doudaki V. Sex and the city in the ambivalent playground of postmodern identity. The Journal of International Communication 18 (2012): 5-17.

9. Mäntymäki M and Salo J. Why do teens spend real money in virtual worlds? A consumption values and developmental psychology perspective on virtual consumption. International Journal of Information Management 35 (2015): 124-134.

10. Qiaolei J. Internet addiction among young people in China: Internet connectedness, online gaming, and academic performance decrement. Internet Research 24 (2014): 2-20.

11. Wang YS. Buyer-seller relationships of the dental devices industry in Taiwan: Perspective of relationship. Journal of Business-to-Business Marketing 25 (2018): 169-186.

12. Demuth C and Mey G. Qualitative Methodology in Developmental Psychology. International Encyclopedia of the Social \& Behavioral Sciences (Second Edition) 2011: 668-675.

13. Wang YS and Hsu TH. Dynamic capabilities of biologics firms in emerging business market: Perspective of dynamic capabilities evident. Industrial Marketing Management 71(2018): 5-18.

14. Wang YS, Lee WL and Hsu TH. Using netnography for the study of role-playing in female online games: Interpretation of situational context model. Internet Research 27 (2017): 905-923.

15. Yin RK (1994). Case Study Research: Design and Methods. 2nd Ed. Thousand Oaks: Sage.

16. Wang YS. Dynamic capabilities in fashion apparel industry: Emergent conceptual framework. Baltic Journal of Management 11 (2016): 286-309.

17. Wang YS. Customer value of adolescents in LINE services: of application grounded hermeneutics. Archives of Psychiatry and Behavioral Sciences 1(2018): 32-39.

18. Wang YS. Addiction by design: Using netnography for user experiences in female online gambling game. International Journal of Human-Computer Interaction 34 (2018): 774-785.

19. Shen C and Chen W. Gamers' confidants: Massively Multiplayer Online Game participation and core networks in China. Social Networks 40 (2015): 207-214.

20. Lin CY, Hung WH, Fang K and Tu CC. Understanding players' achievement values from MMORPGs: an exploratory study. Internet Research 25 (2015): 829-851.

Citation: Yi-Sheng Wang Chao-Feng Lin. Game Addiction is Included in Mental Illness and Medical Care is A Challenge: Textual and Discourse Analysis. Fortune Journal of Health Sciences 1 (2018): 026-030.

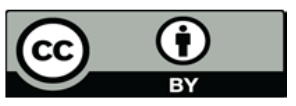

This article is an open access article distributed under the terms and conditions of the Creative Commons Attribution (CC-BY) license 4.0 